\title{
Cardiac rehabilitation in a patient with DeBakey IIIb aortic disecction case report and literature review
}

\section{Rehabilitación cardiaca en paciente con disección aortica DeBakey IIIb reporte de caso y revisión de la literatura}

\author{
Javier Castañeda-López ${ }^{* *}$, Cuauhtémoc Vásquez-Jiménez¹, Liliana Medina-Soto, \\ Claudia M. Ayala-Gutiérrez ${ }^{1}$, Juan de D. Muro-Ortiz² y Vanessa Ramírez-Morineau ${ }^{3}$
}

${ }^{1}$ Unidad de Cardiología y Cirugía Cardiaca de Mexicali, Cardiología/Rehabilitación Cardiaca, Torre de Especialidades Médicas, Hospital Almater, Mexicali, Baja California; ${ }^{2}$ Servicio de Medicina Interna, Hospital Migoo, San Luis Río Colorado, Sonora; ${ }^{3}$ Facultad de Medicina, Universidad de Baja California, Mexicali, Baja California. México

\begin{abstract}
Aortic dissection is one of the three types of acute aortic syndromes, which has a determined mortality rate according to its type. Improvement in survival is possible through diagnostic and treatment advances. However, a great number of these patients frequently experience physical and mental disability after hospital discharge. Thus, we report a case of a woman with aortic dissection diagnosis, who joined a supervised physical training program and a brief review of evidence, demonstrating benefits and safety of cardiac rehabilitation in this pathology.
\end{abstract}

Key words: Cardiac rehabilitation. Aortic dissection. Exercise.

\section{Resumen}

La disección aórtica es uno de los tres tipos de los síndromes aórticos agudos, que tienen una tasa de mortalidad determinada según su tipo. La mejora en la supervivencia es posible debido a los avances en el diagnóstico y el tratamiento. Sin embargo, un gran número de estos pacientes, con frecuencia experimentan discapacidad física y mental después del alta hospitalaria. Por lo tanto, se presenta el caso de una mujer con diagnóstico de Disección Aórtica, que se incorporó a un programa de entrenamiento físico supervisado, así como, una breve revisión de la evidencia, demostrando los beneficios y la seguridad de la rehabilitación cardíaca en pacientes con esta patología.

Palabras clave: Rehabilitación Cardíaca. Disección aortica. Ejercicio.

\section{Correspondencia:}

*Javier Castañeda-López

Unidad de Cardiología y Cirugía Cardiaca de

Fecha de recepción: 13-03-2019

Fecha de aceptación: 10-01-2020

Mexicali, Hospital Almater, Mexicali, Baja California

E-mail: Javiercl_md@ @otmail.com

DOI: 10.24875/ACME.M20000141
Disponible en internet: 06-02-2020 Arch Cardiol Mex. 2020;90(3):282-285 www.archivoscardiologia.com 1405-9940/@ 2020 Instituto Nacional de Cardiología Ignacio Chávez. Publicado por Permanyer. Este es un artículo open access bajo la licencia CC BY-NC-ND (http://creativecommons.org/licenses/by-nc-nd/4.0/). 


\section{Clinical case}

The patient was a 62-year-old female, she was healthy, and did not have any chronic diseases. She started with intense precordial pain, which irradiated to the left scapular region, in association with progressive dyspnea which worsened on exertion, orthopnea, and paroxysmal nocturnal dyspnea.

She was admitted with a hypertensive emergency; therefore, a chest X-ray was taken which revealed thoracic aorta dilatation. A computed tomography angiography was also taken, which demonstrated a DeBakey III-B aortic dissection, with extension to the rise of the left subclavian and right iliac artery, with a rupture in the distal aortic arch.

She underwent a hybrid procedure, which was performed in two phases. First, a left subclavian-carotid bypass with an $8 \mathrm{~mm}$ woven Dacron graft, under a cervical approach and then a retroperitoneal approach of the iliac vessels through hockey stitch incision, with a WD $10 \mathrm{~mm}$ graft implantation, a Valiant Captivia stent was placed in aortic arch's, zone 1, which covered the thoracic aorta $3 \mathrm{~cm}$ above the diaphragm. The angiographic control was successful.

Four days later, she was discharged, with no complications at that moment. Unfortunately, sometime later, she developed motor weakness, predominantly in her left lower limb, and exertion dyspnea which limited her professional activities and daily life.

Therefore, she joined our cardiac rehabilitation program, the initial stress test revealed only chronotropic incompetence. Thus, she was classified as high risk due to chronotropic incompetence, abnormal heart rate, and abnormal systolic blood pressure recovery.

She was prescribed with 24 sessions of aerobic and anaerobic training, with a $96 \mathrm{bpm}$ heart rate target, BORG 12, double product target of 12,840 , and a 4 metabolic equivalents of tasks load. After the 24 sessions, a new stress test was performed to evaluate the program's impact.

The training sessions were performed as follows.

Aerobic exercise. Training sessions on a treadmill were performed, within the pre-established risk and sufficiency parameters, with a workload progression of 3.3 Mets to 5.3 during sessions. The maximum heart rate average of $95 \mathrm{bpm}$ (99\% of prescribed) and double maximum product average of 10,393 ( $83 \%$ of prescribed). There were no cardiovascular adverse events during training sessions.

Anaerobic exercise. Strength, equilibrium, coordination and elasticity with resistance bands, Swiss ball,
Table 1. The results obtained in the initial and final stress test

\begin{tabular}{|l|c|c|c|}
\hline & Initial & Final & Change \\
\hline Date & 06.10 .16 & 16.11 .16 & 40 days \\
\hline Exercise time (min) & $10: 05$ & $14: 55$ & $4: 50$ \\
\hline MET's & 7.0 & 10.2 & 3.2 \\
\hline Basal HR (bpm) & 83 & 68 & -15 \\
\hline Maximum HR (bpm) & 108 & 111 & 3 \\
\hline Reserve HR (bpm) & 35 & 43 & 8 \\
\hline Chronotropic response & 3.4 & 4.2 & 0.8 \\
\hline HR recovery (bpm on $\left.1^{\text {st }} \min \right)$ & 6 & 6 & 0 \\
\hline Maximum DP & 16,200 & 14,430 & 1770 \\
\hline
\end{tabular}

and closed kinetic chain training sessions were performed. They were divided into warm-up, progressive anaerobic exercise in number of reps, and/or load and cooling phase. At the end of the program, there was an improvement in muscular strength per Daniels scale. There was also improvement in orthotic symmetry, tolerance to resistance changes, and a decrease of muscular contracture per Elly's test. All sessions were performed within pre-established risk parameters with no adverse events on training sessions.

An initial stress test was operated to know the patients' cardiovascular state and exercise tolerance. The final stress test focused in knowing the training program's impact, both with modified Bruce's protocol with maximal symptoms, results are shown in Table 1 and Fig. 1.

Therefore, it was concluded that the patient achieved an adequate tolerance to exercise and good progression on load work, which is objectively reflected on the actual stress-test at the programs conclusion. Its safety was finally observed since there were no major cardiovascular events.

\section{Discussion}

The aortic dissection index register in the general population is limited. Some studies suggest 2.63.5 cases $/ 100,000$ people a year. There are predisposing factors such as hypertension, tobacco addiction, dyslipidemia, illicit drug abuse (cocaine, crack), hereditary factor, congenital anomalies specifically Marfan syndrome, bicuspid aortic valve, aortic coarctation, and inflammatory diseases ${ }^{1-3}$. 


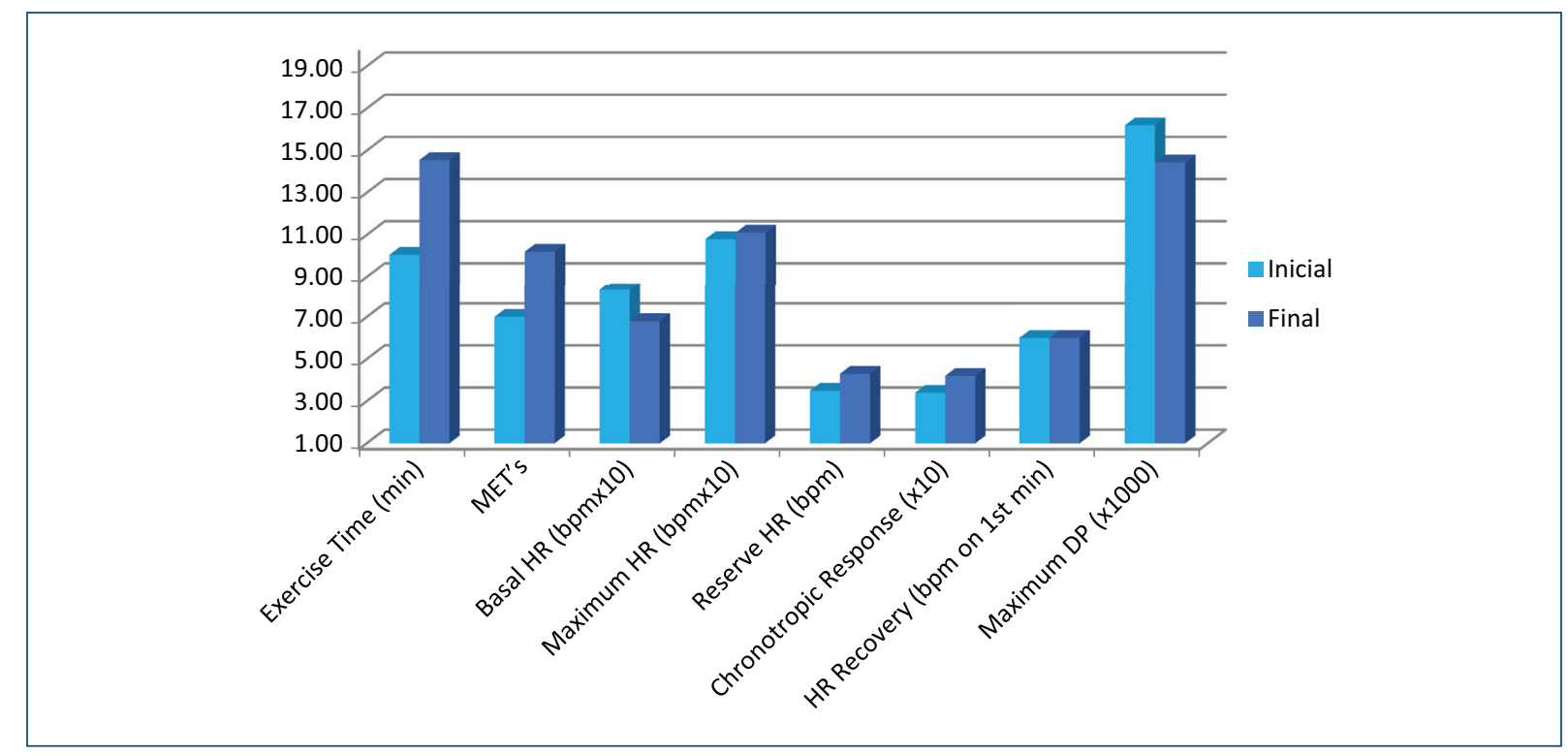

Figure 1. Stress test results.

The acute aortic syndrome is a modern term that embraces dissection, intramural hematoma, and symptomatic aortic ulcer. Classically, aortic dissections require a tear at the intima tunic that is preceded with degeneration and cystic tunica media necrosis. The dissection's spread can be in an anterograde or retrograde manner, which may cause complications such as reversed arterial perfusion syndrome (TRAP), cardiac tamponade, or valvular insufficiency ${ }^{1-3}$.

Aortic dissection is classified per 2 schemes: DeBakey that categorizes dissections per its' origin and extension, DeBakey I: dissection's origin is at the ascending aorta and extends from there distally to aortic arch and descending aorta, DeBakey II: dissection origins and limits to ascending aorta, and DeBakey III: dissection origins on descending aorta and extends distally, (IIla: limited to descending thoracic aorta; IIlb: extends beneath diaphragm). Stanford's stratification system divides dissection in: Type A: ascending aorta; Type B: dissections that do not involve ascending aorta ${ }^{1-3}$.

It has been considered, even with insufficient scientific evidence, that sudden arterial blood pleasure rises could temporarily increase aortic dissection risk and its' frequency in a patient with a previous dissection. That is why it seemed reasonable to decrease physical activities in these patients ${ }^{4}$. However, recent recommendations indicate that patients who had their aorta repaired must do a moderate physical activity with a 3-5 met intensity, $30 \mathrm{~min} /$ day 5 times a week, which assists in a better arterial blood pressure control, cardiovascular health, and a better emotional state ${ }^{5}$.

Many authors have mainly demonstrated that moderate-intensity supervised training programs are safe and in addition, improve cardiovascular and mental health in post-aortic dissection patients ${ }^{4-6}$. Some patients have demonstrated that even intense exercise may be safe?

Chaddha et al., after an extensive review, concluded that although there are not many facts about aortic dissection survivors training programs' safety, it is advisable to perform, since it improves cardiovascular and mental health. Furthermore, they mention that post-aortic dissection patients must be evaluated frequently, to identify adverse signs and symptoms during training sessions, and these facts must be used to adjust medical treatment and major exercise intensity, to enable a better cardiovascular function. It is also recommended that the first training sessions should be supervised by a qualified health personnel ${ }^{4}$.

Delsart et al. showed that a cardiopulmonary stress test is safe in post-aortic dissection patients, including both types $A$ and $B$. They also demonstrated that these patients have great alterations in functional capacity, primarily due to chronotropic incompetence, peripheral deconditioning, and "fear to exercise," which could deteriorate physical capacity even more. For that reason, physical activity is recommended. Training in these patients must be encouraged and supervised in specialized centers to enhance exercise tolerance and to 
subsequently recommend the integration of these activities in their daily life ${ }^{5}$.

\section{Conclusions}

Post-aortic dissection patients suffer an important physical and mental deterioration, much of this is related to low effort tolerance, which is why various authors have proven that physical training programs such as methods for exercise prescription (cardiopulmonary stress test) are safe and recommended to patients with this pathology. Although most of these studies have been done in patients with Type A aortic dissection, even more patients with other types of aortic dissection are included, the recommendation of first training sessions' supervision remains consistent. Nevertheless, there is evidence of the benefits of these programs and it remains a low reference for the inclusion of patients in cardiac rehabilitation.

\section{Ethical disclosures}

Protection of human and animal subjects. The authors declare that the procedures followed were in accordance with the regulations of the relevant clinical research ethics committee and with those of the Code of Ethics of the World Medical Association (Declaration of Helsinki).

Confidentiality of data. The authors declare that no patient data appear in this article.

Right to privacy and informed consent. The authors declare that no patient data appear in this article.

\section{References}

1. Tsai TT, Nienaber CA, Eagle KA. Acute aortic syndromes. Circulation. 2005; $112: 3802-13$.

2. Ince $\mathrm{H}$, Nienaber CA. Management of acute aortic syndromes. Rev Esp Cardiol. 2007;60:526-41.

3. Hiratzka LF, Bakris GL, Beckman JA, Bersin R, Casey E Jr., Carr VD, et al. Guidelines for the diagnosis and management of patients with thoracic aortic disease. Circulation. 2010;121:e266-369.

4. Chaddha A, Eagle KA, Braverman AC, Kline-Rogers E, Hirsch AT, Brook R, et al. Exercise and physical activity for the post-aortic dissection patient: the clinician's conundrum. Clin Cardiol. 2015;38:647-51.

5. Delsart $\mathrm{P}$, Maldonado-Kauffmann $\mathrm{P}$, Bic M, Boudghene-Stambouli $\mathrm{F}$, Sobocinski J, Juthier F, et al. Post aortic dissection: gap between activity recommendation and real life patients aerobic capacities. Int J Cardiol. 2016;219:271-6.

6. Chaddha A, Kline-Rogers E, Braverman AC, Erickson SR, Jackson EA, Franklin BA, et al. Survivors of aortic dissection: activity, mental health, and sexual function. Clin Cardiol. 2015;38:652-9.

7. Bartee S, Shrestha S, Ramos B, Bilbrey T, Carbone P, Schussler JM, et al. Specificity of testing in a cardiac rehabilitation setting resulting in a patient's return to high-intensity outdoor activity following aortic dissection repair. Proc (Bayl Univ Med Cent). 2016;29:151-3. 